\title{
体外分步诱导猕猴胚胎干细胞为肝细胞
}

\author{
金立方 ${ }^{1,2}$, 纪少珲 ${ }^{2}$, 郭祥玉 $^{2}$, 王喜宏 ${ }^{2}$, 季维智 ${ }^{2}$ * \\ (1. 绍兴文理学院 生命科学学院, 浙江 绍兴 312000 ; \\ 2. 中国科学院昆明动物研究所, 云南省动物生殖生物学重点实验室, 云南 昆明 650223)
}

\begin{abstract}
摘要: 采用分阶段诱导方法模拟肝细胞体内发育, 建立体外诱导狝猴胚胎干细胞 (rhesus monkey embryonic stem cells, rESCs）分化为成熟肝细胞的体系，对研究以 ES 细胞为基础的临床替代治疗人类晚期肝脏疾病具有重 要的意义。将 $\mathrm{rESCs}$ 团块在含有 $10 \% \mathrm{FBS}$ 的 DMEM 培养基中悬浮培养 $11 \mathrm{~d}$, 形成含有早期内肧层细胞的拟胚体 （embryonic bodies, EB）并开始表达早期肝细胞的部分基因或蛋白，将 11 日龄 EB 接种至包被有 ECM 的组织培 养血, 分阶段加入 $\mathrm{aFGF} 、 \mathrm{BMP}-4$ 及 $\mathrm{OSM}$ 。经 $\mathrm{aFGF}$ 和 BMP-4 诱导 7 10d 后, 分化细胞形态变为具有双核的多 角形细胞，表达早期和中期肝细胞特异性的蛋白（AFP、ALB 及 CK18）和基因（AFP、ALB、APOH，G-6-P 及 TAT), 并具有储存糖原的功能。撤除 aFGF 和 BMP-4, 添加 OSM 继续诱导 7 10 d, 分化的细胞表达成熟肝细 胞所特有基因 CYP1B1 和 ADH1C, 并具有摄取靛青绿的能力。
\end{abstract}

关键词: 猕猴; 胚胎干细胞; 肝细胞; 细胞因子

中图分类号：Q813；Q959.848 文献标识码：A＼cjkstart文章编号：0254-5853-(2009)05-0509-06

\section{Induction of Rhesus Monkey Embryonic Stem Cells into Hepatocyte-like Cells by a Three-step Method}

\author{
JIN Li-fang ${ }^{1,2}$, JI Shao-hui ${ }^{2}$, GUO Xiang-yu ${ }^{2}$, WANG Xi-hong ${ }^{2}$, JI Wei-zhi ${ }^{2, *}$ \\ (1. College of Life Sciences, Shaoxing University, Shaoxing 312000; \\ 2. Yunnan Key Laboratory for Animal Reproductive Biology, Kunming Institute of Zoology, the Chinese Academy of Sciences, Kunming 650223, China)
}

\begin{abstract}
Embryonic stem cells (ESCs) hold great potential for the treatment of liver diseases. Here, we reported the induction of rhesus monkey ESCs along a hepatocyte lineage by a three-step method. The Rhesus monkey ESCs were suspended in DMEM medium supplemented with 10\% FBS for 11 days to form embryonic bodies (EB) which contained early endoderm or hepatic cells by expression of early hepatic genes. EB of 11 days were transferred into ECM coated dishes and cultured with aFGF, BMP-4 and OSM at different time points for further studies. After induction by aFGF and BMP-4 for 7 - 10 days, the differentiated cells showed a hepatocyte-like morphology, expressed hepatic marker genes (such as AFP, ALB APOH, G-6-P and TAT) and proteins (AFP, ALB and CK18), and possessed the capacity to storage intracytoplasmic glycogen. After further induction with OSM for 7 - 10 days, some cells shared similar characteristics of matured hepatocytes, such as expression of genes of CYP1B1 and ADH1C, and ICG uptaken, indicating the presence of functional hepatocytes in the differentiated cells.
\end{abstract}

Key words: Rhesus monkey; Embryonic stem cells; Hepatocyte-like cells; Growth factors

慢性肝脏疾病是世界性的高发疾病，原位肝移 植是目前治疗此类晚期肝脏疾病的唯一可行办法, 然而由于供体器官的严重不足导致大量患者在等 待中死去。以成体肝细胞移植为基础的细胞替代治 疗是另一种可用于治疗肝脏疾病的可行方案, 但由
于肝细胞资源缺乏、体外培养的肝细胞增殖能力差 等缺点限制了其应用。胚胎干细胞 (embryonic stem cells, ES）因其具有无限的增殖能力和分化为各个 胚层细胞的潜能( $\mathrm{Li}$ et al, 2008), 是细胞替代治疗 临床疾病理想的种源细胞。目前国内外已报道了人

收稿日期：2009-04-01；接受日期：2009-08-25

基金项目：973 计划(2006CB701505；2007CB947701); 中科院创新工程试点经费(KSCX2-YW-R-47); 国家自然科学基金(30570906; 30700159; 30700425)

*通讯作者（Corresponding author）, Tel/fax: 86-0871-5139413, E-mail: wji@mail.kiz.ac.cn 
(Cai et al, 2007; Lavon et al, 2004) 和小鼠 (Gouon-evans et al, 2006; Hamazaki et al, 2001) ES 细胞体外分化为肝细胞或肝样细胞的研究, 这些分 化的细胞在形态上与成体肝细胞相似, 并表达肝细 胞相关的基因和蛋白, 有些分化得到的细胞还具备 肝细胞的功能, 这些研究为以 ES 细胞为种源细胞 进行肝细胞替代治疗研究奠定了良好的基础。

但以人 ES 细胞作为研究材料存在伦理和应用 安全性方面的问题, 而小鼠又与人类种属关系较 远, 非人灵长类是与人类生理功能非常接近的动 物, 因而是人类疾病临床研究的理想替代模型。然 而目前仅有少量的关于非人灵长类动物 ES 细胞体 外诱导分化为肝样细胞的研究, 如 Tsukada et al （2006）报道了 aFGF 在食蟹猴 ES 细胞向肝细胞 分化过程中的作用; Saito et al (2006)采用与小鼠胎 肝细胞共培养的方法诱导食蟹猴 ES 细胞向肝细胞 分化。但是这些肝样细胞在分化的末期仍高水平表 达早期肝细胞的特异基因 AFP, 说明未完全分化成 熟。此外, 一些调控肝细胞发育的细胞因子是否对 猴 ES 细胞来源的肝细胞生成有作用, 也需要进一 步的研究证实。本研究采用分阶段诱导方法建立了 猕猴胚胎干细胞 (rhesus monkey embryonic stem cells, rESCs）体外诱导分化为肝细胞的体系; 对其 形态和功能进行了分析, 同时研究了细胞因子骨成 型蛋白 4(bone morphogenetic protein-4, BMP-4), 酸性成纤维生长因子 (acid fibroblast growth factor, aFGF) 和肿瘤抑制因子 (oncostatin M, OSM) 对 $\mathrm{rESCs}$ 细胞来源的肝细胞发育的影响。

\section{1 材料和方法}

\section{$1.1 \mathrm{rESCs}$ 的培养}

rESCs 细胞系 R366.4 (美国威斯康星大学 Thomson JA 教授馈赠) 培养在用丝裂霉素 ( 5 $\mathrm{ug} / \mathrm{mL}$ ) 处理过的小鼠胎儿成纤维细胞饲养层 (mouse embryonic fibroblasts, MEF) 上。 rESCs 培 养基成分为： $85 \%$ DMEM(Gibco)，15\% dFBS (defined fetal bovine serum, Hyclone), $1 \%$ 非必需氨 基酸(Gibco), $2 \mathrm{mmol} / \mathrm{L} \mathrm{L}$-谷氨酰胺 (Sigma), 0.1 $\mathrm{mmol} / \mathrm{L} \beta$-颈基乙醇, $50 \mathrm{Unit} / \mathrm{mL}$ 青-链霉素(Sigma), 每天换液。每隔 $5 \sim \mathrm{d}$ 用 $10 \mathrm{mg} / \mathrm{mL}$ 的 Dispase (Invitrogen)消化 rESCs 集落, 离心, 重悬后接种到 新铺的 $\mathrm{MEF}$ 上进行传代培养。

\section{2 分步诱导 rESCs 向肝细胞分化}

第一步诱导: 汇合生长的rESCs 细胞用Dispase 消化、离心, $37^{\circ} \mathrm{C} 、 5 \% \mathrm{CO}_{2}$ 悬浮培养于铺有琼脂的 细胞培养血中，培养液为含 $10 \% \mathrm{FBS} 、 1 \%$ 非必需 氨基酸、 $2 \mathrm{mmol} / \mathrm{L} \mathrm{L}$-谷氨酰胺、 $0.1 \mathrm{mmol} / \mathrm{L} \beta$-颈基 乙醇和 $50 \mathrm{Unit} / \mathrm{mL}$ 青-链霉素(Sigma)的DMEM溶 液, 每 $2 \mathrm{~d}$ 更换一次培养液, 收集 5、8、11 日龄拟 胚体(embryonic bodies, EB)用于鉴定分析。第二步 采用无血清诱导: 将 $11 \mathrm{~d}$ 的EB用胶原酶消化成单个 细胞或小细胞团块, 接种到预先包被有 ECM的培 养板上。分化液为: 基础培养液 (DMEM/F12 (1: 1, Gibco)、1×ITS (Gibco)、1.0 g/L牛血清白蛋白 (Sigma)）加 $100 \mathrm{ng} / \mathrm{mL}$ aFGF(Chemicon)和 $20 \mathrm{ng} / \mathrm{mL}$ BMP-4(Chemicon)。第三步诱导: 撤除 aFGF 和 BMP-4, 分化液更换为基础培养液 $+20 \mathrm{ng} / \mathrm{mL}$ $\mathrm{OSM}$ (Chemicon)继续诱导分化 7 10d。

\section{3 免疫细胞化学染色 (ICC)}

用 $4 \%$ 多聚甲醛在室温下固定细胞 $20 \mathrm{~min}, 0.4 \%$ Triton X-100 透膜 $15 \mathrm{~min}$, 用 PBS 冲洗 3 遍后; 加 入 $5 \%$ 的羊血清室温下封闭 $0.5 \mathrm{~h}$, 加入一抗 $37^{\circ} \mathrm{C}$ 捊 育 $40 \mathrm{~min}$ 或 $4^{\circ} \mathrm{C}$ 过夜, 去掉一抗后, PBS 冲洗 3 次, 加入用 Fluorescein isothiocyanate (FITC), Phycoerythin (PE) 或 Texas Red (TR) 标记的二抗 $37^{\circ} \mathrm{C}$ 捊育 $30 \mathrm{~min}$ 或室温作用 $1 \mathrm{~h}$ 。FITC、PE 及 $\mathrm{TR}$ 标记的相应二抗均购于 Santa Cruz 公司。以不添加 一抗, 而添加二抗的细胞作为阴性对照组, 检测二 抗的非特异性结合情况。一抗包括: 甲胎蛋白 ( $\alpha$-fetoprotein, AFP) 鼠抗单克隆抗体 $(1: 200$; Sigma)、白蛋白(albumin, ALB) 鼠抗单克隆抗体 $(1: 200 ;$ Sigma) 、细胞角蛋白 18(Cytokeratin 18,CK18) 鼠抗单克隆抗体(1:200; Sigma), SOX17 鼠抗单克隆抗体 $(10 \mu \mathrm{g} / \mathrm{mL}$; R \& D systems)。染 色后的细胞用 Hoechst33342 或 PI 标记细胞核。免 疫标记的细胞在共聚焦显微镜下 (Zeiss, LSM 510 META）进行检测, 每次实验检测的细胞数大约为 1000 个。

\subsection{RNA提取和RT-PCR}

细胞总 RNA 采用 TRIZOL（Invitrogen）按照 试剂盒的说明书提取。用 DNaseI 消化总 RNA 中可 能含有的基因组 DNA, 去除 DNA 的污染。将提取 的总 RNA $(1 \mu \mathrm{g})$ 在反转录酶的作用下, 反转录成 单链 $\mathrm{cDNA}$ 。用 $1 \mu \mathrm{L} \mathrm{cDNA}$ 作为模板, 加入基因的 特异引物进行 PCR 扩增。 PCR 引物是针对人、小 鼠和大鼠基因的保守序列区域进行设计的（详见表 
1)。3 $3 \mathrm{~L}$ 的 PCR 产物在 $1.5 \%$ 琼脂糖凝胶上进行电 泳, 电泳的条带通过溴化乙啶染色后, 以看家基因 GAPDH 为标准, 用 Quantity-One 软件(Bio-Rad)通 过电泳条带的强弱程度, 评价基因表达量的高低。

\section{5 靛青绿(indocyanine green, ICG)的摄取和排 泌实验}

分化得到的细胞用PBS充分洗涤后, 加入 1 $\mathrm{mg} / \mathrm{mL} \mathrm{ICG} \mathrm{(Sigma)于} 37^{\circ} \mathrm{C}$ 孵育 $30 \mathrm{~min}$, 显微镜下观 察细胞颜色的变化; 再用PBS冲洗2遍, 换回完全培
养液继续常规培养, 并观察细胞颜色的变化。

\section{6 过碘酸一雪夫反应(periodicacid-Schiff，PAS) (糖原染色实验)}

PAS试剂盒(Sigma)用于检测细胞内的糖原。将 涂片滴加固定液固定 3 5 min, 水洗, 晾干; 滴加过 碘酸于涂片上氧化 $10 \mathrm{~min}$, 水洗, 晾干; 放入雪夫 氏溶液中, 置 $37^{\circ} \mathrm{C}$ 水温箱 $5 \sim 10 \mathrm{~min}$; 取出后流水洗 涤10 20 min, 晾干, 镜检。

表 1 RT-PCR 的引物序列及产物大小

Tab. 1 Information of primers used in RT-PCR

\begin{tabular}{|c|c|c|}
\hline 名称 Name & 长度 Length (bp) & 引物序列 Primer sequence (5' to 3') \\
\hline \multirow{2}{*}{$A D H 1 C$} & \multirow{2}{*}{451} & Forward: TGGAGCAGCCAGAATCAT \\
\hline & & Reverse: AGAGCGAAGCAGGTCAAA \\
\hline \multirow{2}{*}{$A F P$} & \multirow{2}{*}{216} & Forward: GCTGGATTGTCTGCAGGATGGGGAA \\
\hline & & Reverse: ACAATGGCATGGTTGGTTGAG \\
\hline \multirow{2}{*}{ Albumin } & \multirow{2}{*}{760} & Forward: GTGAGACCAGAGGTTGATGTG \\
\hline & & Reverse: CATTCATGAGGATCTGCAGCG \\
\hline \multirow{2}{*}{$\mathrm{APOH}$} & \multirow{2}{*}{357} & Forward: GCACTGAGGAAGGAAAATGG \\
\hline & & Reverse: GGCCATCCAGAGAATATCCA \\
\hline \multirow{2}{*}{ CYP1B1 } & \multirow{2}{*}{306} & Forward: GAGAACGTACCGGCCACTATCACT \\
\hline & & Reverse: GTTAGGCCACTTCAGTGGGTCATGAT \\
\hline \multirow{2}{*}{ G6P } & \multirow{2}{*}{334} & Forward: GAAATGAGGATGGAGGAA \\
\hline & & Reverse: AGGTTACAGGGAACTGCT \\
\hline \multirow{2}{*}{ GAPDH } & \multirow{2}{*}{451} & Forward: TGAAGGTCGGAGTCAACGGA \\
\hline & & Reverse: TGGTGCAGGAGGCATTGCTG \\
\hline \multirow{2}{*}{ TAT } & \multirow{2}{*}{424} & Forward: AAACCTGCCTACAGACCC \\
\hline & & Reverse: GCTGAACACTGACCCACA \\
\hline
\end{tabular}

\section{7 统计分析}

统计数据 (3 次重复) 以平均值 \pm 标准误 $(\mathrm{SE})$ 进行表示。统计分析采用 SPSS10.0 软件进行 LSD (least-significant difference, 最小显著差数法) 分 析。 $P<0.05$ 为差异显著。

\section{2 结 果}

\section{$2.1 \mathrm{rESCs}$ 的培养及 $\mathrm{EB}$ 的形成}

培养在 MEF 上的 rESCs 具有典型的胚胎干细 胞的形态特征, 细胞呈圆形或椭圆形, 核质比高, 细胞排列紧密, 细胞之间界限明确 (图片未显示)。 消化后的 rESCs 细胞团块在含 $10 \%$ FBS 的 DMEM 培养液中悬浮培养形成 $\mathrm{EB}$, 收集不同日龄 $\mathrm{EB}$ 。以 早期肝细胞的特异性蛋白 AFP 作为标志检测 5、8、 11 日龄 $\mathrm{EB}$ 的发育情况。染色结果显示, 11 日龄 EB 有少量细胞可明显表达早期内肧层细胞特异性 蛋白 AFP(图 1C), 而 5 日龄(图 1A)和 8 日龄 EB(图 1B)中则未检测到 AFP 的表达, 进一步检测发现 11
日龄 EB 还表达内胚层细胞特异性蛋白 SOX17(sex determining region Y -box 17, SRY-box 17)(图 1D)。 RT-PCR 结果同样显示 11 日龄的 EB 开始低表达 AFP、APOH(apolipoprotein H)及 ALB 这几种早期 肝细胞的基因，而未表达中期或成熟肝细胞的相关 基因如: 6-磷酸葡萄糖(glucose-6-phosphate, G-6-P)、 乙 醇脱氢酶 $1 \mathrm{C}($ alcohol dehydrogenase $1 \mathrm{C}$, ADH1C)、酪氨酸 $-\alpha$-酮戊二酸转氨酶（tyrosine aminotrans-ferase, TAT) 及细胞色素 P450 1B1(cytochrome P450 1B1, CYP1B1)(图 2)。以上结 果说明, 11 日龄 $\mathrm{EB}$ 含有内胚层细胞并开始向早期 肝细胞分化, 因此我们选用这一时期的 EB 做进一 步的诱导分化。

\section{2 aFGF 及 BMP-4 诱导生成中期肝细胞}

将 11 日龄 $\mathrm{EB}$ 用胶原酶消化成单个细胞或小细 胞团块后, 接种于铺有 $\mathrm{ECM}$ 的 4 孔板中, 在含 $\mathrm{aFGF}$ 和 BMP-4 的无血清培养体系中贴壁分化。7 10 d 后, 贴壁的细胞呈典型的上皮细胞形态，有些细胞 

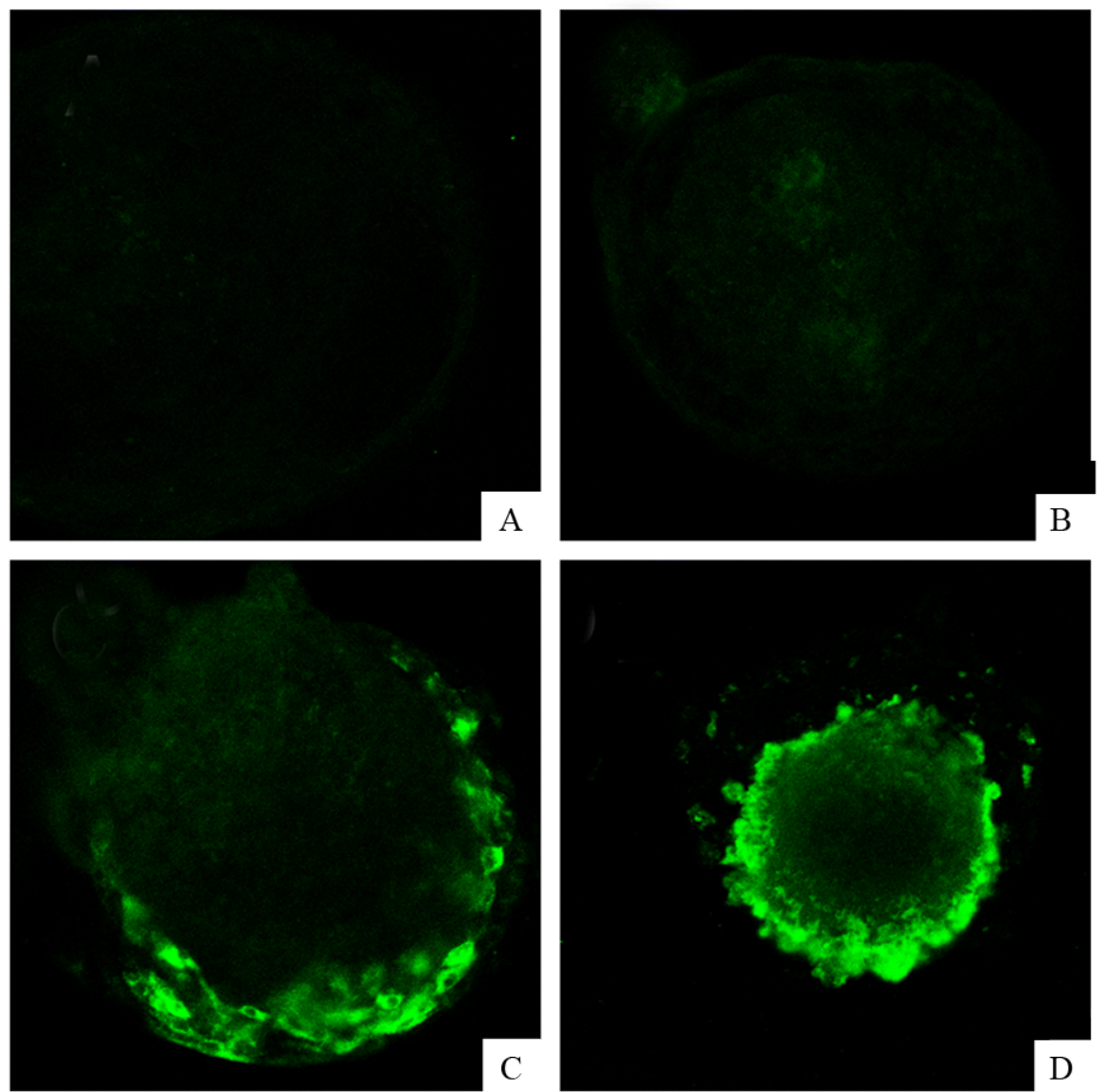

图 1 不同日龄 $\mathrm{EB}$ 的免疫苂光染色

Fig. 1 Fluorescent images of EBs collected on different stages

5 日龄(A)和 8 日龄(B)EB 不表达 AFP；11 日龄 EB 表达 AFP (C) 及 SOX17(D)。(A-D×200)。

EBs collected on day 5 (A) and 8 (B) did not express AFP; while day 11 EB expressed AFP (C) and SOX17 (D). (A-D×200)

出现了肝细胞所特有形态(图 3A)。这些分化的细胞 表达早期或中期肝细胞特异蛋白, 如 AFP、ALB 及 CK18 (图 3C, D, E)和 mRNA, 如 G-6-P 和 TAT (图 $2)$, 并具有储存糖原的功能(图 3B), 但不表达成熟 肝细胞特异性基因 ADH1C 及 CYP1B1(图 2), 也不 具有摄取靛青绿的能力, 说明分化的细胞还未发育 到成熟的肝细胞阶段。以 PAS 阳性为标准, 数据统 计显示超过 70\%的细胞呈 PAS 阳性(图 3B)。而对照 组则出现混合的细胞形态, 以成纤维样细胞居多(图 3a), 只有 $10 \%$ 左右的 PAS 阳性细胞(图 3b)。以上 结果说明 aFGF 和 BMP-4 能显著提高 EB 向肝细胞 分化比率。

\subsection{OSM 促使体外分化的肝细胞发育成熟}

小鼠体内肝细胞的发育结果显示, OSM 是肝细 胞发育成熟的重要因子(Kinoshita \& Miyajima, 2002)。因此, 我们进一步探索 OSM 是否也同样可 以促进体外诱导的肝细胞的分化与成熟。经 $\mathrm{aFGF}$
和 BMP-4 诱导后的细胞在含 $20 \mathrm{ng} / \mathrm{mL}$ OSM 的无血 清培养液中继续诱导 7 10d。在 OSM 处理后, 约 有 $30 \%$ 的分化细胞具有摄取和排泌 ICG 的能力(图 3F), RT-PCR 结果表明, 分化的细胞开始表达成熟 肝细胞的相关基因, 如(ADH1C 和 CYP1B1, 图 2), 与此相对应的是早期肝细胞的蛋白 AFP 表达消失, 提示肝细胞已趋于成熟。以上结果说明 OSM 可促 使体外诱导的肝细胞的成熟分化。

\section{3 讨 论}

定向诱导胚胎干细胞分化为包括肝细胞在内 的成体细胞是目前生物学领域的研究热点。目前胚 胎干细胞向肝细胞分化的研究多集中在小鼠和人 的 ES 细胞上, 在其它物种上研究的相对较少。包 括狝猴在内的非人灵长类是与人类生理功能非常 接近的实验动物, 可用于临床前研究, 以避免伦理 问题。本研究利用 rESCs 体外模拟了肝细胞的发育 
过程, 利用胚胎干细胞在体外一定条件下可自发形 成具有三个胚层的类胚体的特性, 得到了含有早期 内胚层及少量的早期肝细胞的类胚体, 这些细胞在

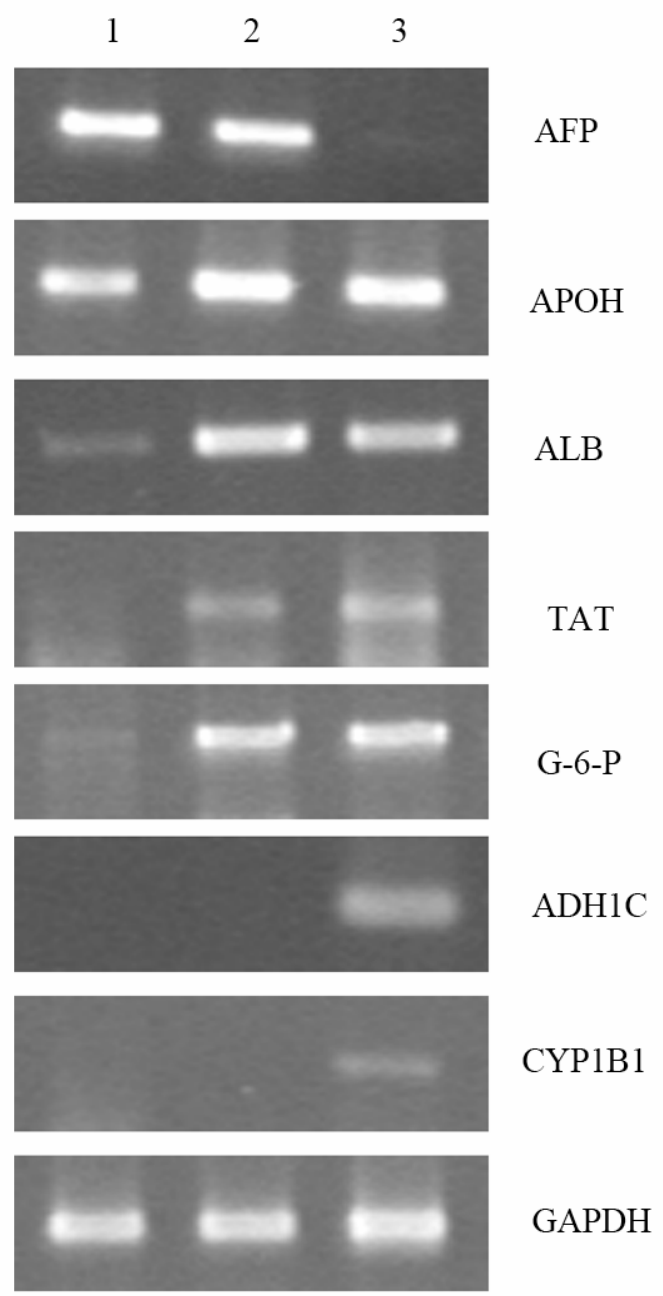

图 2 肝细胞相关基因 mRNA 在不同诱导时期的细胞 中的表达

Fig. 2 Expression of hepatic related mRNA in differentiated cells at different stages

泳道 1 是诱导分化 11 日龄的 $\mathrm{EB}$; 泳道 2 是经 $\mathrm{aFGF}$ 及 BMP-4 诱导分 化 7 10d 的细胞; 泳道 3 是经 OSM 诱导分化 7 10d 的细胞。GAPDH 作为内参。

Lane 1: Day $11 \mathrm{~EB}$; lane 2: Cells treated with aFGF and BMP-4 for 7 - 10 days; and lane 3: Cells induced by OSM. Expression of GAPDH mRNA was used as internal control.

aFGF 和 BMP-4 的诱导下向肝细胞定向分化, 经 OSM 的进一步诱导发育为具有成熟肝细胞特性的 细胞。这一实验结果将有助于推进以胚胎干细胞为 基础的替代治疗人类肝脏疾病的研究。

$\mathrm{EB}$ 是胚胎干细胞在体外一定条件下自发形成 的类似早期胚胎的球体结构, 其三胚层的形成与分 化基本模拟了体内胚胎早期发育分化的过程, 可作
为研究哺乳动物早期胚胎发育的理想体外模型 (Lavon \& Benvenisty, 2005)。不同日龄的 EB 对肝 细胞的生成效率有影响, $\mathrm{EB}$ 日龄太早, $\mathrm{EB}$ 中存在 的内胚层细胞太少; 而 $\mathrm{EB}$ 日龄太晚, 内胚层细胞 已开始向组织细胞分化; 这两种情况都将导致分化 效率的降低。我们利用 11 日龄的 EB 作为研究材料 是因为此时期的 $\mathrm{EB}$ 三个胚层已基本形成, 此外早 期肝细胞的特异性蛋白 AFP 和内胚层特异性蛋白 SOX17 也在这一时期的 EB 中出现, 说明 11 日龄 的 EB 已具备向肝细胞分化的潜能, 是较为合适的 用于诱导肝细胞分化的 $\mathrm{EB}$ 。

由 $\mathrm{EB}$ 进一步诱导分化得到了与体内肝细胞形 态特征相似的细胞, 并且表达肝细胞相关的一系列 蛋白和基因, 如 AFP、ALB 及 $\mathrm{APOH}$ 。然而, 这些 基因除了在肝细胞中表达外，同样也在来源于胚外 内胚层的卵黄囊细胞中表达 (Asahina et al, 2004)。 在卵黄囊细胞中, AFP 是主要的分泌蛋白, 其表达 量不会随着发育的进行下降; 但在肝细胞中 AFP 的 表达模式刚好相反, 在早期的肝细胞中高表达, 随 着肝细胞的逐渐成熟其表达量逐渐下降, 在成熟的 肝细胞中则不表达（Asahina et al，2004）。我们的 研究结果显示, AFP 大约在 EB 分化的第 $11 \mathrm{~d}$ 开始 表达, 而在 aFGF 和 BMP-4 诱导后中期肝细胞中表 达升高, 在 OSM 诱导的得到的成熟肝细胞中表达 量又开始下降, 这一过程与 AFP 在体内发育中肝细 胞的表达过程相吻合。这些结果证实分化得到的细 胞为肝脏细胞, 而非来源于原始内胚层的卵黄囊细 胞。此外, 这一结论也被其它与肝细胞发育相关 的一些特异性性状所证明, 分化得到的细胞表达 CYP1B1 和 ADH1C 及具有摄取 ICG 的能力, 而这 一能力只有在成熟的肝细胞中才具有(Lavon et al, 2004; Yamada et al, 2002), 原始内胚层来源的卵黄 囊细胞则没有。同时我们认为分化得到的肝细胞是 一个逐渐成熟的过程, 早期分化得到的细胞表达早 期肝细胞相关基因 AFP、ALB 及 APOB，但并不表 达发育中期的肝细胞基因 G-6-P 和 TAT 及成体肝细 胞基因 ADH1C 和 CYP1B1; 而经 aFGF 和 BMP-4 诱导后, 分化的细胞开始表达 G-6-P 及 TAT 并具有 储存糖原的功能; 经 OSM 进一步的诱导后, 分化 的细胞表达成熟肝细胞所特有的基因 ADH1C 和 CYP1B1，并具有摄取和排泌 ICG 的功能。

aFGF 和 BMP-4 被证实在小鼠胚胎由限定性内 胚层向早期肝细胞特化中起关键作用, 抑制其作用 

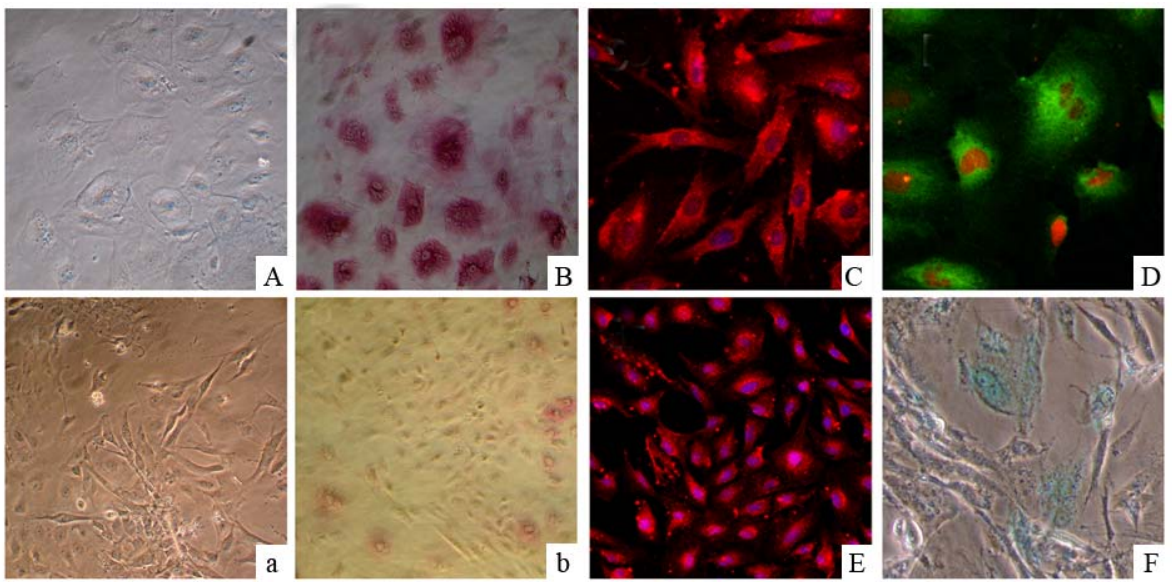

图 3 分化细胞的形态及苂光检测

Fig. 3 Phase contrast and fluorescent images of differentiated cells induced by growth factors $\mathrm{aFGF}$ 和 BMP-4 诱导的部分细胞呈现典型肝细胞的多角形态 (A), 超过 70\%的细胞储存糖原的功能 (红色, B); 对照组 (不添加 aFGF 及 BMP-4) 细胞出现较多的成纤维样细胞(a), 只有约 10\%的细胞储存糖原的功能(b)。aFGF 和 BMP-4 诱导的细胞表达 AFP (C), A ALB (D)及 CK18 (E)。F:经 OSM 进一步诱导后的细胞具有成熟肝细胞摄取和排泌 ICG 的功能（绿色）。 A-F $\times 200$ 。

Differentiated cells induced by aFGF and BMP-4 showed typical hepatocytic morphology with bi-nuclear (A), more than $70 \%$ of cultured cells were stained positive for PAS (B); while in the control group, fibroblasts cells were present (a) and only about $10 \%$ of cultured cells were stained positive for PAS (b). aFGF and BMP-4 treatment cells expressed AFP (C), ALB (D) and CK18 (E). F: OSM treatment differentiated cells acquired the capacity of ICG uptake, which is the function of matured hepatocytes. A-F $\times 200$.

后将导致特化的肝细胞数量下降; 而 OSM 的作用 则表现在使特化的肝细胞分化成熟(Kinoshita \& Miyajima, 2002)。在体外, 人和小鼠 ES 细胞向肝细 胞分化及成熟过程中也需要上述细胞因子的参与 (Cai et al, 2007; Gouon-Evans et al, 2006)。Tsukada et al (2006)的研究结果发现 aFGF 可促进食蟹猴 ES 细 胞向肝细胞分化; 但 BMP-4 和 OSM 在狝猴肝细胞

\section{参考文献:}

Asahina K, Fujimori H, Shimizu-Saito K, Kumashiro Y, Okamura K, Tanaka Y, Teramoto K, Arii S, Teraoka H. 2004. Expression of the liver-specific gene Cyp7a1 reveals hepatic differentiation in embryoid bodies derived from mouse embryonic stem cells[J].Genes Cells, 9(12): 1297-1308.

Cai J, Zhao Y, Liu YX, Ye F, Song ZH, Qin H, Meng S, Chen YZ, Zhou RD, Song XJ, Guo YS, Ding MX, Deng HK. 2007. Directed differentiation of human embryonic stem cells into functional hepatic cells [J]. Hepatology, 45(5): 1229-1239.

Gouon-Evans V, Boussemart L, Gadue P, Nierhoff, Koehler CI, Kubo A., Shafritz DA, Keller G. 2006. BMP-4 is required for hepatic specification of mouse embryonic stem cell-derived definitive endoderm [J]. Nat Biotechnol, 24(11): 1402-1411.

Hamazaki T, Iiboshi Y, Oka M, Papst PJ, Meacham AM, Zon LI, Terada N. 2001. Hepatic maturation in differentiating embryonic stem cells in vitro [J]. FEBS Lett, 497(1): 15-19.

Kinoshita T, Miyajima A. 2002. Cytokine regulation of liver development [J]. Biochim Biophys Acta, 1592(3): 303-312.

Lavon N, Benvenisty N. 2005. Study of hepatocyte differentiation using embryonic stem cells [J]. J Cell Biochem, 96(6): 1193-1202.

Lavon N, Yanuka O, Benvenisty N. 2004. Differentiation and isolation of
发育中的作用目前还未有报道。在这里, 我们的研 究发现, 与对照组相比, 联合使用 aFGF 和 BMP-4 可以提高 rESCs 细胞向肝细胞分化比率, OSM 则 可使分化得到的肝细胞进一步成熟, 这一结果与已 有的报道相一致(Gouon-Evans et al, 2006; Hamazaki et al, 2001), 说明不同物种间肝细胞发育模式是相 似性的。

hepatic-like cells from human embryonic stem cells [J]. Differentiation, 72(5): 230-238.

Li RR, Chen HW, Chen DL, Wang SF, Zhang J, Chen R, Ji WZ. 2008. Hepatocyte growth factor promotes the proliferation of neural progenitors derived from rhesus monkey embryonic stem cells [J]. Zool Res, 29(5): 518-528. [李荣荣, 陈洪伟, 陈栋梁, 王淑芬, 张 敬, 陈 锐, 季维智. 2008. 肝细胞生长因子促进狝猴胚胎干细胞来源 的神经前体细胞的增殖. 动物学研究, 29(5): 518-528.]

Saito K, Yoshikawa M,Ouji Y, Moriya K, Nishiofuku M, Ueda S, Hayashi N, Ishizaka S, Fukui H. 2006. Promoted differentiation of cynomolgus monkey ES cells into hepatocyte-like cells by co-culture with mouse fetal liver-derived cells [J]. World $J$ Gastroenterol, 129(42): 6818-6827.

Tsukada H, Takada T, Shiomi H, Torii R, Tani T. 2006. Acidic fibroblast growth factor promotes hepatic differentiation of monkey embryonic stem cells [J]. In Vitro Cell Dev Biol Anim, 42(3-4): 83-88.

Yamada T, Yoshikawa M, Kanda S, Kato Y, Nakajima Y, Ishizaka S, Tsunoda Y. 2002. In vitro differentiation of embryonic stem cells into hepatocyte-like cells identified by cellular uptake of indocyanine green [J]. Stem Cells, 20(2): 146-154. 